\title{
Entrevista com Celso Furtado
}

\author{
Rosa Maria Vieira*
}

Celso Furtado é um dos mais expressivos e conhecidos pensadores nacionais contemporâneos, responsável por uma obra teórica original e vigorosa no campo da análise econômica. Aliás, o surgimento da moderna Economia Política no Brasil confunde-se com sua trajetória como economista. Formado na escola de pensamento da CEPAL, levou a América Latina subdesenvolvida à condição de objeto de análise, dedicando-se à teorização do capitalismo na periferia, tendo sempre o Brasil, no entanto, como referência.

Dentre suas contribuições essenciais encontram-se a sistematização teórica do fenômeno do subdesenvolvimento como uma manifestação específica da expansão capitalista mundial, e a interpretação do processo de industrialização dos países periféricos em termos de substituição de importações.

Formado em Direito na Universidade do Brasil (hoje UFRJ), e tendo feito o doutorado em Economia Política em Paris, Celso Furtado integrou a primeira geração de economistas da CEPAL que, liderada por Raúl Prebisch, deu vida ao que ficou conhecida como escola estruturalista econômica latino-americana.

Seu percurso intelectual, inicialmente construído na projeção de políticas públicas de desenvolvimento para a América Latina, sofreu uma inflexão decisiva ao final dos anos 1950, quando ganhou dimensões prioritariamente nacionais. Foi por esta época que Celso Furtado passou a integrar o Grupo de Trabalho para o Desenvolvimento do Nordeste (GTDN), no governo de Juscelino Kubitschek, responsável

* Créditos da autora 
pelo lançamento da Operação Nordeste, de onde se originaram o Conselho de Desenvolvimento do Nordeste (CODENO) - transformado, logo a seguir na SUDENE -, e o mais importante plano de desenvolvimento capitalista para a região. Ainda no Brasil, Celso Furtado esteve à frente do Ministério Extraordinário do Planejamento durante o período presidencialista de João Goulart, responsabilizando-se pela elaboração do Plano Trienal.

Sua carreira política de administrador público foi interrompida pelo Golpe Militar de 1964, quando, na primeira lista de homens públicos cassados pela ditadura, foi forçado a partir para o exílio: primeiro para o Chile, a seguir para os EUA, para se instalar, finalmente, na França, onde construiu uma carreira acadêmica internacional.

$* * *$

Em princípio, a obra de Celso Furtado pode ser vista como um marco fundamental no pensamento econômico contemporâneo à medida de seu esforço em levar, por vias teóricas originais, o mundo subdesenvolvido à categoria de reflexão científica. Suas contribuições, em termos de uma teoria de formação do capital industrial na periferia, conformam um enfoque específico dos processos econômicos do qual emerge uma visão globalizadora incomum entre os economistas de seu tempo. No plano da formulação econômica, procura apresentar-se, sobretudo, como o economista e o planejador que, valendo-se do instrumental macroeconômico keynesiano, indaga sua época e tece projetos para o Brasil com os olhos na História e os pés no Terceiro Mundo.

Celso Furtado influenciou de modo decisivo o pensamento social brasileiro, situando-se como necessária referência no debate teóricoideológico que animou a cena nacional nos anos 50 e 60. A ele coube caracterizar a transição da economia agro-mercantil para a urbano-fabril, em termos de substituição de importações, elaborar a teorização do subdesenvolvimento brasileiro e protagonizar, a partir de sua atuação político-institucional, alguns dos momentos decisivos na implementação do processo de acumulação industrial no país.

Entre suas obras mais importantes destacam-se:

A economia brasileira. Rio de Janeiro: A Noite, 1950.

Formação econômica do Brasil. Rio de Janeiro: Fundo de Cultura, 1959. 
A Operação Nordeste. Rio de Janeiro: ISEB, 1959.

Desenvolvimento e subdesenvolvimento. Rio de Janeiro: Fundo de Cultura, 1961

A pré-revolução brasileira. Rio de Janeiro: Fundo de Cultura, 1962.

Dialética do desenvolvimento. Rio de Janeiro: Fundo de Cultura, 1964.

Subdesenvolvimento e estagnação na América Latina. Rio de Janeiro: Civilização Brasileira, 1966.

Teoria e politica do desenvolvimento econômico. São Paulo: Cia. Editora Nacional, 1967.

Um projeto para o Brasil. Rio de Janeiro: Saga, 1968.

Análise do "modelo" brasileiro. Rio de Janeiro: Civilização Brasileira, 1973.

O mito do desenvolvimento econômico. Rio de Janeiro: Paz e Terra, 1974.

Prefácio à nova Economia Política. Rio de Janeiro: Paz e Terra, 1976.

Criatividade e dependência na civilização industrial. Rio de Janeiro: Paz e Terra, 1978.

Cultura e desenvolvimento em época de crise. Rio de Janeiro: Paz e Terra, 1984.

Brasil, a construção interrompida. São Paulo: Paz e Terra, 1992.

Obra autobiográfica de Celso Furtado. São Paulo: Paz e Terra, 1997.

O capitalismo global. São Paulo: Paz e terra, 1998.

O longo amanhecer: reflexões sobre a formação do Brasil. São Paulo: Paz e Terra, 1999.

Em busca de um novo modelo: reflexões sobre a crise contemporânea. São Paulo: Paz e Terra, 2002.

\section{***}

Esta entrevista foi realizada no apartamento de Celso Furtado, na cidade do Rio de Janeiro, na tarde de 6 de agosto de 2001, e revista por ele em julho de 2002. O propósito era, sobretudo, buscar o esclarecimento de alguns caminhos de sua formação teórica, de certas leituras e, principalmente, de possíveis influências intelectuais não declaradas, que ficaram à sombra de seus trabalhos autobiográficos.

A entrevista serviu, posteriormente, como material de pesquisa à tese de doutoramento da autora em História Social, pela PUC-SP Celso Furtado: Reforma, Política e Ideologia (1950-1964). 
Rosa Maria Vieira: Professor, entre os intelectuais brasileiros, o senhor é um dos pensadores que mais expôs sua biografia intelectual à cultura internacional. Fez o doutorado na França, viveu a experiência da CEPAL (Chile), passou por Cambridge etc. Porém, eu gostaria de começar nossa entrevista perguntando sobre as influências nacionais, sobre os pensadores brasileiros que considera relevantes para sua formação, que o influenciaram, pelo menos, inicialmente.

Celso Furtado: Não é fácil responder a esta questão, porque não me recordo de ter sido influenciado por um pensador brasileiro. Não houve um autor brasileiro que eu admirasse propriamente, com a força com que admirei Facundo, de Sarmiento. Na verdade, fui influenciado profundamente por certos homens de ação, como o economista argentino Raúl Prebisch. Conheci-o quando saí do Brasil e fui trabalhar na CEPAL. Eu já estava querendo interpretar o subdesenvolvimento, o porquê do desenvolvimento atrasado na América Latina. No Brasil, tenho uma dívida com alguns estudiosos do país, a começar pelo Simonsen.

RM: Roberto Simonsen?

CF: Sem a obra de Roberto Simonsen eu nunca teria escrito Formação econômica do Brasil. É interessante lembrar que Simonsen reuniu um material riquíssimo sobre o período colonial brasileiro. Ele não passou do período colonial, mas foi tão abundante o material que recolheu, que quem quiser pensar o Brasil dessa época deve partir dele. No Nordeste, o autor que provavelmente mais me impressionou, de forma diferente de Simonsen, foi Gilberto Freyre. Gilberto pensava o Nordeste, li com interesse seu clássico Casa-grande e Senzala.

Mas não aceitei a visão do Brasil de Gilberto. Era esta uma visão conservadora e que, de alguma maneira, legitimava o escravismo, marca definitiva do Brasil. Sua obra era uma legitimação sutil desse estado de coisas, mas ainda assim ajudou-me a pensar a sociedade brasileira, libertando-nos do enfoque racista que até então dominava o pensamento brasileiro. Nina Rodrigues, grandes escritores como Euclides da Cunha, e muitos outros, eram racistas, influenciados por um pensamento de cunho racista vindo da Europa e que aqui se implantou. Mas também desde cedo houve uma reflexão contrária a essas idéias. Gilberto Freyre é o seu vetor: teve a oportunidade de estudar nos Estados Unidos no momento em que a antropologia social avançava com Franz 
Boas. Gilberto herdou de Boas uma visão muito moderna do problema racial. Foi a que trouxe para o Brasil. Guardei dele algumas influências, como guardei de Roberto Simonsen o conhecimento factual da economia brasileira na época colonial.

RM: O senhor, em uma entrevista dada, em 1997, a Maria da Conceição Tavares, Manuel Correia de Andrade e Raimundo Pereira sobre o Nordeste, refere-se a Guimarães Duque como seu mestre. Eu gostaria que o senhor falasse a respeito...

CF: Ele me influenciou pelo lado da ecologia. Era um agrônomo, com grande formação científica, um pesquisador.

RM: Ele é contemporâneo da SUDENE?

CF: Sim, foi contemporâneo da SUDENE. Mas era mais ou menos da geração de Gilberto Freyre. Guimarães Duque foi um estudioso do problema do clima do Nordeste. Foi ele quem primeiro expôs com clareza a realidade desse clima, das chamadas "secas", mostrando que a periodicidade destas era um dado da natureza perfeitamente superável pelo homem. Foi ele que me orientou no estudo dos problemas ecológicos do Nordeste. Eu só entendi o Nordeste a partir do conhecimento da obra dele.

RM: Voltando a Gilberto Freyre... No seu Auto-retrato intelectual, em dado momento o senhor cita Gilberto Freyre como o pensador que teria lhe revelado a sociologia americana. Isto procede? E em que medida?

CF: É exatamente o que eu disse acima. A influência que Boas teve sobre Gilberto refletiu-se em nós. Era mais antropologia do que sociologia. Tratava-se de compreender que a dimensão cultural era independente da etnia, da raça: liberar os pensadores brasileiros do preconceito de raça, que era uma sujeição mental. O próprio Euclides da Cunha sofreu essa tirania doutrinária do racismo. Entretanto, ele a superou - fugindo um pouco à tirania da ciência da época, quase como num passe de mágica -, porque Os Sertões foi resultado de contato direto com o povo brasileiro. Foi quando ele percebeu que esse povo em nada era inferior que, impressionado, começou a acreditar no Brasil. Estudar o Brasil, nessa época, era algo complicado, pois ainda havia quem acreditasse em "raça degenerada", um típico entulho intelectual.

RM: Este entulho, o senhor está se referindo às teorias raciais? 
CF: Elas eram aceitas como a ciência mais sofisticada. Entretanto, era, na verdade, uma forma de submeter-se ao imperialismo europeu, em época que Europa dominava o mundo...

RM: O senhor cursou Direito na Universidade do Brasil, formando-se em 1944. Eu tenho muita curiosidade, como historiadora, de saber o que se lia, em termos do pensamento social no Brasil, na Faculdade de Direito. De que autores, que o tenham marcado naquele momento de formação, o senhor se lembra?

CF: Quando estudei Direito, minha orientação já era para Economia. Mas não havia, no Brasil, curso superior de Economia. Comecei a ler História Econômica e diversos livros de Economia, em espanhol, pois foi quando surgiu o Fondo de Cultura Económica, do México, que publicava muitas obras, como por exemplo a de Max Weber, a que tive acesso. Li Max Weber durante os anos da faculdade: a sua obra Economia e Sociedade. Mas não li somente sociologia, li muita Economia também, que o Fondo de Cultura publicava abundantemente. Essa editora foi uma revolução cultural na minha geração. Nós, que estávamos limitados a uma bibliografia francesa, tivemos acesso a uma profusão de obras de autores de outras línguas.

RM: De que obras o senhor se lembra?

CF: Lembro-me, por exemplo, da obra de Alfred Weber, História da Cultura, que me impressionou muito, embora fosse de alcance limitado. Ainda assim, abriu-me horizontes. Havia obras específicas de Economia, de autores de língua inglesa, que nessa época já chegavam ao Brasil. Eu já lia um pouco de espanhol desde rapazinho porque em minha casa havia uma enciclopédia em espanhol em vinte volumes, que meu pai havia comprado. Mas meu pai, lá no Nordeste, me advertia de que se eu quisesse conhecer o mundo, tinha de saber inglês. Ele contratou um professor - um inglês, Mr. Vance - para me dar aulas práticas de inglês. Mas as obras de Economia mais facilmente chegavam ao Brasil em versão espanhola, graças ao fantástico esforço feito no México para traduzi-las. Esse trabalho de divulgação do Fondo de Cultura deve-se ao sociólogo José Medina Echavarría, que anos depois eu convidei para integrar os quadros da CEPAL.

RM: Ah, o senhor é que...

CF: Fui a Porto Rico conversar com ele, pois andava entusiasmado com sua obra Sociologia da Cultura. 
RM: Que outros interesses o senhor tinha nos anos universitários?

CF: Nessa época comecei a estudar os problemas do planejamento, por influência de autores norte-americanos. Fordismo, taylorismo, organização racional do trabalho: tudo ia me levando ao planejamento. Nessa época escrevi um trabalho intitulado Trajetória da democracia na América, que mostrava como as instituições políticas tinham evoluído nos Estados Unidos. Inscrevi-o num concurso do Instituto Brasil-Estados Unidos e só algum tempo depois, quando eu já estava na França fazendo meu doutorado, em 1948, soube que o ensaio havia sido premiado pelo IBEU. Ganhei uma boa quantia e o Instituto publicou o trabalho. Conto isso para mostrar o variado horizonte das minhas leituras nos anos de estudos universitários. Há, porém, uma tônica: a idéia de Estado, de organização do trabalho e, fundamentalmente, de administração pública.

Paralelamente aos estudos de Direito, fui jornalista da Revista da Semana, uma precursora das newsweeks. Meus pais me mandavam algum dinheiro, mas eu precisava trabalhar. Um dia, Cleanto de Paiva Leite, que era meu primo, indagou por que eu não fazia um concurso para o serviço público. Era algo que nunca tinha me passado pela cabeça. Mas aceitei fazê-lo, passei em primeiro lugar, fui nomeado para o DASP como assistente de organização, e, mais tarde, como técnico de administração. Assim, comecei no serviço público, onde me dediquei a estudar organização e administração. Foi então que compreendi que me faltava um conhecimento mais sistemático de Economia.

RM: Professor, quando o senhor era aluno de Direito, uma série de autores trabalhavam com a problemática da construção nacional, com a idéia de viabilização do Brasil como nação, numa vertente conservadora: Sílvio Romero, Alberto Torres, um pouco antes, e, depois, Oliveira Viana e Azevedo Amaral, que, aliás, tinha um projeto de industrialização, numa proposta de modernização conservadora. Eu gostaria de saber se o senhor teve contato, em termos de leitura, com estes pensadores?

CF: No caso de Sílvio Romero, havia um ranço racista que eu rejeitava. Azevedo Amaral não me impressionou. Oliveira Viana foi diferente...

RM: Por quê? O que chamou sua atenção?

CF: A visão de conjunto que ele tinha do Brasil. Oliveira Viana, que, aliás, conheci pessoalmente - visitei-o em sua casa, para conversar 
com ele -, me impressionou bastante. Mas a verdade é que o pensamento brasileiro estava marcado por esse fundo de racismo.

RM: Esta era a grande questão que os separava...

CF: Daí eu ter me inclinado para a vertente da modernidade, que levava à idéia de planejamento.

RM: O senhor referiu-se ao seu interesse pela questão da organização, do planejamento. Pois bem, na obra de Oliveira Viana, o Estado tem um papel muito importante dentro do arranjo social, e eu lhe pergunto se isto, em algum momento, o sensibilizou, ou melhor, se aquela visão de Estado, que organiza a realidade social, o tocou?

CF: Tocou, mas não chegou a ter um efeito permanente. A verdade é que cheguei à visão do Estado pela via do planejamento. Percebi a importância da ação organizada do Estado, e da necessidade de uma política. Tudo isso me vinha do estudo da teoria da organização. Escrevi um trabalho, na época, que teve uma certa repercussão. Chamava-se Sobre Planejamento e nele eu estudava a organização de um time de futebol em campo. Suas regras são fluidas, cada jogador as interpreta como quer, mas elas são essenciais para a vitória. Esse trabalho foi traduzido para o espanhol e publicado na Argentina. Foi quando comecei a ter uma certa presença...

RM: Isto foi antes do ingresso na CEPAL?

CF: Ah, bem antes!

RM: E antes mesmo do senhor fazer o doutorado na França?

CF: Muito antes.

RM: Existem alguns clássicos da modernidade brasileira, Gilberto Freyre, a que o senhor já se referiu, Sérgio Buarque de Holanda e Caio Prado Jr. - Francisco de Oliveira, inclusive, o coloca ao lado desse terceto. Com relação a Caio Prado, eu acho que tanto o senhor como ele, por vertentes diversas, têm algumas preocupações comuns, como, por exemplo, a questão da particularidade do capitalismo no Brasil. Uma outra coisa é a idéia de economia colonial que aparece como uma preocupação, uma categoria de análise imperante em seu pensamento e no do próprio Caio Prado. Eu queria perguntar precisamente o seguinte: o senhor tem, em algum momento na sua trajetória, algum contato, aproximação, leitura ou diálogo com a obra do Caio Prado?

CF: Não. A obra Formação do Brasil Contemporâneo, só fui lê-la já na França, preparando minha tese de doutorado. Acho-a muito interessante, 
tendo-a citado extensamente em minha tese. Essa tese vai sair agora, publicada em português, cinqüenta anos depois. Um historiador da Unicamp a descobriu em Paris e me pediu licença para publicá-la.

RM: Tamás Szmrecsányi...

CF: Ele conseguiu uma cópia da tese. Eu tinha perdido o único exemplar que trouxe da França em 1948. Recentemente, mexendo em meus papéis, descobri os originais da tese, escritos à mão em português. Meu orientador de tese, o professor Maurice Byé, conhecia perfeitamente a nossa língua e, para apressar a sua redação, permitiu-me escrevê-la inicialmente em português. É esse original que está sendo publicado.

RM: Maurice Byé esteve aqui no Brasil, não?

CF: Esteve durante vários anos, como professor. Ele era muito simpático, me ajudou muito. A tese se chama Economia colonial no Brasil nos séculos XVI e XVII.

RM: É nela que o senhor fez aquele estudo comparativo entre a produção do açúcar no Nordeste e na região das Antilhas... Eu gostaria de saber que autores brasileiros o senhor utilizou na Economia colonial? O senhor se referiu há pouco a Caio Prado. E o Capistrano?

CF: Capistrano de Abreu, um pouco. Mas nessa altura eu já estava muito voltado para a leitura econômica. Guardei de Capistrano apenas algumas idéias gerais, porque sempre fui contra sua idéia fixa do São Francisco como o "rio da unidade nacional". A unidade nacional não se fez com o São Francisco.

RM: Eu queria lhe perguntar, ainda, sobre algumas outras leituras. Por exemplo, João Lúcio de Azevedo. O senhor passou pelo Épocas de Portugal Econômico?

CF: Passei e citei na minha tese...

RM: O João Normando?

CF: Ah sim, citei, também, na tese o Normando, que é dos Estados Unidos, não?

RM: E o senhor usou o Leroy-Beaulieu, que tem toda aquela teorização sobre colônia de povoamento.

CF: Também.

RM: E, já que estamos falando de leituras, eu quero perguntar, também, sobre Manoilesco e List.

CF: Tomei conhecimento de Manoilesco um pouco mais tarde, quando ele teve muita repercussão no Brasil. 
RM: ...inclusive a FIESP financiou a tradução de seu livro sobre o protecionismo para a indústria.

CF: Sim, a tradução a partir do francês, não é? Li esse livro com curiosidade. Aliás, Prebisch fora influenciado por ele. A obra de Manoilesco tem coisas muito positivas. Mas o que ficou foi o corporativismo, que tem aspectos muito negativos. Como as duas vertentes do pensamento dele não foram separadas, sua influência tendeu a diminuir.

RM: Isso provavelmente deve ter partido de críticas do pensamento liberal, digamos assim.

CF: Exato... Mas, os dirigentes da FIESP perceberam a importância da teoria do protecionismo, do moderno protecionismo.

RM: Se me lembro bem, o Roberto Simonsen cita, freqüentemente, o Manoilesco em seus trabalhos.

CF: É... ele foi traduzido e difundido por influência de Simonsen.

RM: E List, o teórico alemão?

CF: Eu fiz só uma resenha sobre o livro dele, que trata da Alemanha. Aliás, tudo que permitia entender o atraso do Brasil me interessava. Manoilesco, por exemplo, me permitia mostrar que o Brasil não podia seguir pelo caminho em que estava. Ele propunha um sistema de proteção do setor moderno de produção e List foi o grande teórico que influenciou Manoilesco. List é de 1840, 1850, e sua obra foi definitiva, porque criou o conceito de indústria infantil. Ele procurava mostrar que toda indústria é frágil no começo e que, portanto, precisa de proteção. Todas essas idéias foram se estruturando em minha cabeça, como uma forma nova de pensar. Mas a influência maior que tive foi de Keynes.

RM: Nessa entrevista dada à Maria da Conceição Tavares e ao Manuel Corrêa de Andrade, lá pelas tantas, o senhor disse algo que me chamou muito a atenção: que a CEPAL tinha sido sua escola de trabalho como economista. Eu queria, então, lhe perguntar se sua aproximação mais intensa com o pensamento de Keynes ocorreu quando passou a fazer parte da CEPAL. Gostaria que me falasse um pouco, também, sobre suas relações intelectuais com Raul Prebisch.

CF: A verdade é que o pensamento de Prebisch foi fundamental para mim. A experiência da CEPAL me permitiu constatar que o Brasil era um país atrasado, e para isso não havia explicação. Isso eu descobri assim que cheguei a Santiago, comparando as estatísticas do Brasil, da Argentina, do México, do Chile. 
RM: No Fantasia Organizada o senhor fala sobre isto...

CF: Trato disso, sim. Fui encarregado de fazer um mapeamento do desenvolvimento dos países mais importantes da América Latina durante dez anos. Ao fazer esse trabalho, constatei o quanto o Brasil era atrasado. Como explicar? O Brasil tinha mais território, mais população, mais recursos e potencial. Onde estava a sua inferioridade? Superada a teoria da inferioridade racial, a resposta só podia estar na História, e lá fui buscá-la. Tudo isso me obrigou a repensar, a abrir um caminho. E comecei a ver o fim do túnel quando li Keynes.

RM: E onde se deu esta aproximação com Keynes, professor?

CF: Na CEPAL.

RM: Na CEPAL? O senhor começou por aquele livro do Prebisch, sobre Keynes?

CF: Não.

RM: é que ele tem um livro...

$\mathrm{CF}$ : ...um pequeno livro feito nessa época.

RM: Isso!

CF: Não posso dizer que descobri Keynes na CEPAL, porque já o havia estudado antes. Mas até então, eu via o Keynes da "teoria do ciclo econômico", que era a sua grande contribuição e levava à política de estabilização. Na CEPAL, comecei a perceber a importância da visão macroeconômica da História. Tratava-se, agora, de olhar a História, vendo o macroeconômico, para entender a lógica do atraso e descobrir os fatores que impediam o crescimento de um país como o Brasil. Aí, comecei a ler teoria econômica mais sofisticada.

RM: Em suas análises, a questão do Estado tem um papel central. O senhor tem uma leitura sobre a intervenção do Estado no Brasil que é paradigmática. Neste sentido, queria lhe perguntar sobre a importância do François Perroux. Ele tem algum papel no momento em que o senhor começa a definir a questão da importância do Estado?

CF: O pensamento de François Perroux foi seguramente o que mais me influenciou, pela importância de sua teoria do "pólo de crescimento", que permite compreender que o crescimento econômico resulta de uma vontade política. Perroux me orientou para pensar o papel do Estado. É a partir da criação do Estado Nacional que se pode falar de desenvolvimento.

RM: O senhor se lembra o que leu de Perroux, em especial? 
CF: A Economia do Século XX, aqueles grandes volumes... Mas eu também fui aluno de Perroux, em Paris, segui suas conferências. Ele lecionava na mesma faculdade onde fiz o doutorado. Assistir a uma aula de Perroux era um espetáculo, porque ele fazia uma gesticulação muito curiosa. Aliás, lembro-me de que ele foi acusado de ter sido collabo... sem fundamento. Seus próprios pares da Universidade o absolveram.

RM: Professor, o seu caminho para descoberta do papel do Estado é um caminho que foi sedimentado pelo Keynes ou pelo Perroux?

CF: Por Perroux. Keynes, em relação à questão do Estado, dá, digamos assim, a sinalização do ponto de vista econômico. É o teórico da dinâmica macroeconômica. Na realidade, ele criou a necessidade de uma dinâmica. O modelo keynesiano é um modelo estático, mas é claro que na sua época representou um tremendo avanço. Keynes valorizou o papel do Estado. A partir dele cabia pensar em política econômica e não mais, simplesmente, no mercado para regular a economia. Foi um salto enorme. Isso nos deixou fascinados: o Brasil era atrasado porque não havia uma política econômica e o mercado não iria resolver os problemas do país. Ia deixar o Brasil onde estava, acumulando cada vez mais atraso. A ruptura qualitativa na minha visão do mundo dá-se aí: compreender o papel do Estado, perceber que o desenvolvimento, no fundo, é obra de uma ação política, e que essa ação política poderia ter sido facilitada por uma certa estrutura social, uma classe burguesa dinâmica, como houve na Europa...

RM: O que não era o caso do Brasil...

CF: De fato. Aqui a classe dirigente era passiva, dominada intelectualmente de fora. Havia que se formar uma vontade política. Passei, então, a ver o mundo como um desafio. Fazer política é enfrentar desafios. Não cabe esperar por soluções espontâneas. Não pode haver infra-estrutura sem política, sem planejamento. O mercado é maravilhoso, mas não transforma a infra-estrutura a médio e longo prazos.

RM: Numa de suas entrevistas recentes o senhor disse uma frase muito significativa: "Não há mercado sem Estado".

CF: Exato. Penso, por exemplo, nas cidades italianas do passado. Uma cidade como Veneza foi um verdadeiro Estado nacional, regida por uma vontade política que defendia os seus interesses para valer. 
RM: Professor, ainda dentro desta linha, eu encontrei no seu Auto-retrato intelectual algumas referências a Mannheim, quanto à questão do planejamento democrático. Pelo que eu estou percebendo, o senhor pensou, originalmente, a questão do planejamento na Faculdade de Direito, quando entrou em contato com a preocupação americana com a administração. Mas, há um dado momento em que Mannheim aparece em seu pensamento. Gostaria de saber até onde o senhor reconhece a influência de Mannheim nessa questão do planejamento democrático. E, também, uma outra coisa: até onde a noção de intelligentsia de Mannheim influenciou suas concepções a propósito dos intelectuais?

CF: Para mim, Mannheim foi fundamental. Ele me iluminou, me tirou do tecnicismo. Pude perceber que há valores, que o planejamento não decorre apenas de uma boa estratégia. Há que estar iluminado por valores, para ser democrático. Mannheim me ensinou a ver a sociedade como um sistema de valores, antes de tudo.

RM: Quando se dá este contato o pensamento de Mannheim?

CF: Muito cedo, na época em que chegavam aqui as traduções de suas obras feitas pelo Fondo de Cultura. Eu estava na Faculdade de Direito. O livro de Mannheim publicado por essa época, início da Segunda Guerra, foi Ideologia e Utopia. Havia outro livro dele sobre planificação social, mas eu me concentrei no Utopia...

RM: Essa idéia, essa concepção de intelectual que o senhor tem, como alguém capaz de intervir...

CF: É inspirada em Mannheim... No conceito de intelligentsia...

RM: Isso, exatamente... Gostaria de saber, agora, se o senhor teve contato com a obra do Parsons?

CF: Muito superficialmente, nada que me influenciasse. Quem me iluminou mesmo foi Mannheim, foi Ideologia e Utopia.

RM: Em 1958, o senhor se afasta da CEPAL e vai passar uma temporada em Cambridge. Gostaria de saber, inicialmente, quais as razões de seu afastamento da CEPAL. Num dos livros autobiográficos, o senhor faz referências a isto, mas não ficou muito claro. E uma outra coisa... Há, em determinado momento, uma sugestão de que a elaboração de A economia brasileira, de algum modo, acirrou alguns problemas dentro da CEPAL. Queria saber se o seu afastamento tem alguma coisa a ver com mudanças nos rumos da instituição, ou com a elaboração do A Economia Brasileira? 
CF: É algo de que prefiro não tratar. Quando escrevi esse livro, Prebisch não gostou, não aprovou.

RM: Por quê?

$\mathrm{CF}$ : Porque ele achava - mandou-me dizer indiretamente - que os técnicos da CEPAL deviam todos pensar pela instituição. O que escrevessem era para a instituição, o que me pareceu um absurdo. Mas era o temperamento dele.

RM: Ele era muito centralizador?

CF: Muito centralizador. Então, em 1954, quando publiquei esse livro, comecei a cogitar em encerrar minha carreira na CEPAL. Pensei: "eu não posso ficar, porque eu quero escrever, ter liberdade de pensar; não vou ficar preso a uma administração”. Por isso em 1957 tirei uma licença por um ano e fui pra Cambridge.

RM: Não houve rompimento?

CF: Não houve um rompimento formal. Passei um ano em Cambridge, onde aproveitei para escrever o Formação Econômica do Brasil, que já estava todo elaborado no meu espírito. Mas já pensava em voltar para Brasil... Quando voltei, disse a Prebisch que só me interessaria uma missão no Brasil. Ele queria que eu fosse para Santiago. Renunciei, então, à CEPAL, deixando o cargo, após ter passado nove anos na instituição..

RM: Para entender e me aproximar do seu pensamento, eu li, obviamente, muitas coisas elaboradas pela CEPAL, no momento em que Prebisch estava na direção. Pude perceber uma diferença marcante entre as colocações de Prebisch e as suas. Não vi a presença da História no pensamento de Prebisch. No meu entender, esta seria uma grande diferença...

CF: Havia mesmo uma diferença muito grande. Você observou bem. Prebisch não captava o fenômeno histórico. Ele era mais um técnico. Via a Economia como economista. Em segundo lugar, ele não via a dimensão social com a mesma urgência que eu. Ele vinha de um país, a Argentina, onde havia muito crescimento social. O povo vivia bem. Os operários comiam churrasco, na rua, em Buenos Aires... E eu vinha do Brasil, do Nordeste. Tinha uma percepção da pobreza, tinha urgência! Havia diferenças, mas isso não impedia que colaborássemos. Eu era um grande admirador de Prebisch, devo muito a ele. A CEPAL foi um momento importante. Mas, de qualquer maneira, eu queria atuar 
no Brasil. E, de fato, ao me desligar da CEPAL, de volta ao Brasil fui trabalhar pelo Nordeste.

RM: É o momento em que aparece a SUDENE...

CF: O Nordeste estava, como sempre, enfrentando problemas. Foi uma fase da vida em que me orientei para repensar o Brasil. Passei quase dez anos nas Nações Unidas, estudei muito os outros países latino-americanos, dirigi grupos de trabalho na CEPAL, fiz, por exemplo, um trabalho de quase 200 páginas sobre a economia mexicana, a sua crise de pagamentos. Todos esses estudos me ajudaram a melhor entender o Brasil, pois ao estudar países parecidos, eu enxergava melhor a nossa realidade. Daí querer me dedicar diretamente ao Brasil.

RM: Professor, será que eu poderia dizer que esse seu vínculo com a História, que o Raul Prebisch não tem, que essa sua aproximação com a cultura humanística, que vai representada, por exemplo, pelo pensamento de Mannheim, que isso pode ser explicado pelo fato do senhor ter um projeto para o Brasil?

CF: Eu sempre fui apaixonado pela História. Não sei por que não fui historiador. Numa recente exposição sobre a minha obra, foi mostrado um diário meu de juventude, de quando eu era estudante no Liceu da Paraíba. Nesse diário eu escrevia: “meu propósito é escrever um livro para explicar o Brasil, é repensar a história do Brasil”.

RM: Na época do Liceu?!

CF: Sim. Repensar a história do Brasil, com os conhecimentos modernos daquela época, com as ciências sociais, por exemplo, para entender o Brasil.

RM: Quantos anos o senhor tinha?

CF: No máximo 17 anos. O documento está datado. Portanto, vem de longe essa mania... Eu lia tudo sobre história e me beneficiei do fato de meu pai ter arrematado uma biblioteca com notáveis livros de história. Por exemplo, eu tinha em casa os 20 volumes de Cesare Cantù. Eu li muita história, era meu prazer.

RM: A História veio antes da Economia...

CF: A História chegou primeiro. A Economia veio como que para explicar e entender melhor a História. Eu já disse isso num livro de memórias. Compreendi que só entenderia bem a História se soubesse Economia. Portanto, fui para Economia para entender a História. Isso 
foi influência do grande historiador belga Henri Pirenne. Citei tanta gente, que me esqueci dele...

RM: O senhor faz referência a Pirenne, muito claramente...

CF: Pirenne foi fundamental para mim. Pensar, buscar uma lógica na História, que não fosse a do acaso, apenas. Entender a História... este era meu grande desafio. Mannheim, Pirenne eram teóricos que me ajudaram a entender a História.

RM: Alguém, inclusive, já afirmou que a dúvida é saber se o senhor é um historiador que se vale da Economia, ou um economista que não prescinde da História...

CF: É verdade. Tanto assim que meu livro Formação Econômica do Brasil é um "esqueleto" de História. Minha paixão era a História, era entender a vida dos homens, dos homens vivendo, criando, inventando. Quanto à Economia, há uma frase clássica que diz que ela é "a anatomia da sociedade". Compreendi que a única forma de se entender bem a História era me armar de conhecimentos econômicos. Vem daí a atração pela teoria do ciclo econômico, por Schumpeter, que eu conheci bastante...

RM: E o Myrdal, professor?

CF: Também li bastante Gunnar Myrdal.

RM: Como o senhor situa o peso do pensamento de Myrdal em sua formação?

CF: Eu diria que Schumpeter e Myrdal foram os dois pensadores econômicos com visão ampla que mais me influenciaram. Houve outros também, como Pirenne, historiador, que estudou a história da Europa para compreender o feudalismo e entender a decadência do Império Romano. Isso me apaixonava, e sobre isso escrevi em Economia Brasileira, e também em Desenvolvimento e Subdesenvolvimento. Faço aí uma análise do desenvolvimento econômico do capitalismo, e mostro como a decadência de Roma e o atrofiamento das cidades do Império Romano levaram ao declínio da atividade econômica. A paixão por entender a História é seguramente o elemento mais importante da minha vida intelectual.

RM: Professor, qual o significado de Cambridge para a sua formação intelectual?

CF: Cheguei a Cambridge após muitos anos de trabalho na CEPAL, trazendo muitas idéias e também muitas dúvidas na cabeça; agora, 
poderia esclarecê-las, discutir com o mundo acadêmico tão sofisticado dessa universidade. O professor Nicholas Kaldor foi quem me levou para Cambridge. Certa vez, conversando comigo no México, disse-me: "você tem de ir para lá". Instigou-me assim a entender a economia moderna, globalmente. Tenho a impressão de que Cambridge me permitiu conferir certas coisas, dar maior precisão à minha linguagem, ser mais rigoroso na análise econômica.

RM: E a Joan Robinson?

CF: Joan Robinson teve muita influência sobre mim, li muito seus livros. Joan era uma grande amiga pessoal.

RM: O senhor estava como professor visitante?

CF: Bem, dessa vez não... Em 1957 e 1958, eu fiquei em Cambridge como fellow. Era um pesquisador com liberdade para seguir os cursos que quisesse, sem nenhuma obrigação sistemática. Era um estágio para pensar e escrever alguma coisa. Foi aí que escrevi o Formação Econômica, justifiquei o desatino... (risos)

RM: Em Desenvolvimento e Subdesenvolvimento há um texto escrito tendo em vista um concurso na Universidade do Brasil. Eu queria saber o que ocorreu, quais foram as dificuldades desse processo de inserção acadêmica?

CF: Enquanto eu fui candidato não fizeram o concurso (risos). A cátedra era ocupada por uma pessoa que tinha força suficiente para barrar o concurso. E assim, durante vários anos, fui candidato sem conseguir fazer o concurso. Quando, em 1964, fui cassado, então fizeram o concurso...

RM: E quem ocupava esta cátedra?

CF: Quem ocupou a cátedra depois de 64 não foi a mesma pessoa que me criou as dificuldades. Foi o João Paulo Almeida Magalhães. Quem criou dificuldades foi outra pessoa, um professor interino, que bloqueou o concurso por muito tempo. Quando fui para o exílio, essa pessoa também se afastou, ou seja, não tirou tanto proveito assim. Mas o concurso foi aberto e o João Paulo, que tinha competência, ganhou.

RM: Nos anos 60, quais eram as suas relações com os intelectuais do PCB? Havia algum contato, alguma forma de aproximação?

CF: Bem, eu tinha vários amigos dentro do PC. Mas nem sempre se declaravam comunistas quando falavam comigo. Por exemplo, o Acioli Borges, um engenheiro muito amigo, lá da Paraíba. Talvez o 
Américo Barbosa de Oliveira fosse ligado indiretamente. Esse pessoal não era do PC abertamente; eles eram influenciados pelo PC... me procuravam, me consultavam etc. Oficialmente nunca tive contato com o PC.

RM: E o ISEB? O senhor fez algumas palestras...

CF: Fiz algumas palestras no ISEB, mas nunca fui propriamente daquele grupo... eu era da CEPAL, nessa época. Dei uns cursos no ISEB. É curioso... fiquei muito amigo de algumas pessoas de lá, como o Hélio Jaguaribe, além de muitos outros...

RM: Álvaro Vieira Pinto?

CF: O Álvaro Vieira Pinto nunca foi muito próximo de mim. Ele era um filósofo muito fechado, voltado para si mesmo...

RM: Werneck Sodré?

CF: Conheci rápida e superficialmente. Nunca tive trato com ele. $\mathrm{Na}$ verdade, o fato é que eu não tive oportunidade de me meter com o PC. Quando poderia ter entrado, estava fora do Brasil. A sedução que o PC exercia, durante a guerra, era muito grande. Sedução de pensar o Brasil de outra maneira, agir de outra forma, criar uma história nova etc. Tudo isso seduzia muita gente. Mas, nesse período fui convocado para o Exército e fui para a guerra. Ou seja, estava fora do Brasil quando ocorreu o grande crescimento do PC. Portanto, não me procuraram... Depois, voltei para o Brasil, por muito pouco tempo, retornando para estudar na Europa.

RM: Por suas características de pensador independente, dificilmente o senhor sobreviveria ou se manteria lá dentro, de camisa-deforça...

CF: Exato. Eu provavelmente teria brigado. Mas nunca fui contra o PC, sempre tive simpatia pelos comunistas. Eram pessoas idealistas, dispostas a sacrifícios, a lutar. Embora me parecessem iludidos, achando que tinham soluções prontas para todos os problemas, tudo lhes parecia muito fácil. Na teoria econômica nunca aceitei a influência do PC. Mas, com meu viés historicista, tinha afinidades com eles.

RM: E as questões do Estado e da economia de mercado interno?

CF: Fui leitor atento de Marx. Fui dos poucos brasileiros a estudar Marx, sistematicamente, em Paris. Estudei lá os quatro volumes de O capital, em francês. Queria anotar tudo. Fiz esse curso de marxismo no Instituto de Ciências Políticas, com o professor Cornu. Vez por 
outra ele dizia (e achava graça), "tem um brasileiro muito afeito ao estudo do marxismo"...

RM: Mas, eu me lembro de ter lido em A fantasia organizada que sua visão desse professor de marxismo o deixava...

CF: ...assustado pelo primarismo. Eu até o apresentei de uma forma um pouco caricatural. Os alunos brincavam com ele, que não percebia... Mas é importante dizer que na época em que eu estudei em $\mathrm{Pa}$ ris, o curso de marxismo era aberto, todos podiam segui-lo. Entretanto, o marxismo nunca me seduziu, propriamente, como uma doutrina. A grande sedução do marxismo estava na sua macroeconomia, que era pioneira: poder olhar a sociedade como um todo. Mas, quando eu cheguei a ela, já tinha passado por Keynes, cuja macroeconomia era mais sofisticada. Portanto, não fui influenciado. Mas rendi minhas homenagens. Você leu sobre as minhas influências e Marx estava entre elas. Creio que todo mundo que pensou a sociedade moderna foi influenciado por Marx, pois sua visão ampla é extraordinária.

RM: Professor, estou encerrando a entrevista e gostaria de fazer uma última pergunta, bem ampla. O que o Brasil deve a Celso Furtado e o que Celso Furtado deve ao Brasil?

CF: Bem, a primeira parte da pergunta eu creio que não cabe a mim responder. Você e os estudiosos do Brasil devem saber. A única coisa que eu percebo é que o interesse pelo que escrevi mantém-se firme. Meus livros circulam, prossegue o debate das idéias e dos problemas que lancei. Eu, na verdade, devo enormemente ao Brasil. Poucas pessoas contam com a oportunidade de ter à vista um laboratório tão fantástico como é o Brasil. Possuímos a mescla racial, cultural, a vastidão do território; estudar a evolução de tudo isso é apaixonante. Por isso me preocupa o futuro deste país. Que ele consiga sobreviver às transformações que o mundo hoje sofre! Os Estados nacionais estão mudando muito. Até onde iremos nessa mudança, não sei! Minha confiança (minha intuição) é de que o país já é bem consistente para sobreviver.

RM: ...para resistir?

CF: ...para resistir. Já tem consistência. Aspectos que, às vezes, parecem de menor relevância, como os esportes, "salvam" os brasileiros, a consciência nacional. Um jogador de tênis, ou de futebol, pode virar um herói nacional. É uma prova de que o Brasil existe. Isso me conforta... 
RM: Li outro dia um artigo de um professor chamado Juarez Guimarães, da Universidade Federal de Minas Gerais. E ele recorre a Hegel, para falar a seu respeito. Ele diz o seguinte: "Está em Hegel o pensamento de que a palavra amor dita por um jovem não tem o mesmo valor expressivo do que quando formulada por um homem entrado da derradeira fase da vida". A sua maior declaração de amor é uma declaração de amor ao Brasil - isto se percebe claramente. Essa coerência que o senhor teve ao longo de sua vida... coerência e obstinação...

CF: Isto eu digo, é o meu destino. Nasci no Sertão...

RM: Professor, eu quero lhe agradecer muito, acho que foi um privilégio poder entrevistá-lo. Eu queria, inclusive, lhe contar uma coisa: o primeiro livro "sério", acadêmico, que li na minha vida, quando eu tinha 17 ou 18 anos, foi o Formação Econômica do Brasil. Foi aí, com certeza, que descobri a vocação para historiadora...

CF: É um livro difícil...

RM: De fato, eu me lembro que nas primeiras leituras pouco entendia, mas havia alguma coisa de fascinante lá dentro, que era a idéia de ver um Brasil diferente. Nas minhas aulas de História, a visão de Brasil que eu passei para os meus alunos foi a visão de Celso Furtado.

CF: Muito obrigado... 